\title{
A LOGISTICA REVERSA, SUSTENTABILIDADE E EFIÊNCIA ENERGÉTICA
}

Nelson da Silva, Claudio José Donato, Irene Caires da Silva

Universidade do Oeste Paulista - UNOESTE, MBA em Logística, Presidente Prudente, SP. E-mail: nelsonguto@gmail.com; claudio.donato@hotmail.com; irene@unoeste.br

\section{RESUMO}

O objetivo desta pesquisa é de analisar a importância da logística reversa e sua sustentabilidade, verificando-se a participação da empresa em preservar o meio ambiente, com ações sustentáveis e contribuindo para o bem estar da sociedade e do nosso planeta, voltada para o reaproveitamento dos materiais utilizados e para o aumento da eficiência energética. A metodologia utilizada neste trabalho foi de pesquisa bibliográfica, destacando o conceito de logística reversa para as atividades de reciclagens de materiais, métodos quantitativos e qualitativos, apresentando dados de reciclagem referente ao programa conta cidadã, projeto troca de resíduos sólidos por bônus na conta de energia realizada pelas empresas cooperadas da Energisa.

Palavras-chaves: logística reversa, reciclagem, sustentabilidade, eficiência energética.

\section{REVERSE LOGISTICS, SUSTAINABILITY AND ENERGY EFFICIENCY}

\section{ABSTRACT}

The objective of this research is to analyze the importance of reverse logistics and their sustainability, verifying the participation of the company in preserving the environment, with sustainable actions and contributing to the well being of society and our planet, aimed at the reuse of Materials used and to increase energy efficiency. The methodology used in this work was a bibliographical research, highlighting the concept of reverse logistics for materials recycling activities, quantitative and qualitative methods, presenting recycling data regarding the citizen's account program, solid waste exchange project for energy account bonuses By the cooperative companies of Energisa.

Keywords: reverse logistics, recycling, sustainability, energy efficiency.

\section{INTRODUÇÃO}

A logística reversa vem gradualmente ganhando destaque em cinco fatores que influenciam as organizações na logística reversa: econômico, ambiental, tecnológico, social e legal. As empresas estão cada vez mais investindo na gestão do ciclo de vida de seus produtos e serviços, percebe-se que os avanços tecnológicos vêm contribuindo na fabricação de novos produtos de forma ágil e constante, ou seja, essa mesma tecnologia permite que tais produtos tornem-se rapidamente obsoletos e descartáveis, contribuindo para a degradação e poluição do meio ambiente.

As organizações vêm adotando uma conduta mais ativa em relação ao meio ambiente, elas estão mudando a postura inerte em oportunidades de negócios. Ter um negócio sustentável e ser sustentável, todavia, é uma exigência do mercado. Os que descobrirem-se os caminhos para se diferenciar serão beneficiados, ganharão seu espaço dentro do mercado, agregarão valor a seus 
processos e a sua competitividade. Neste contexto é de suma importância trazer para discussão a questão da logística reversa.

O objetivo desta pesquisa foi de analisar a importância da logística reversa e sua sustentabilidade, constatando-se a participação das organizações em conservar o meio ambiente, com ações sustentáveis e contribuindo para o bem estar da sociedade e do nosso planeta. O meio ambiente vem se tornando cada vez mais o centro de discussões e idéias. Muito se tem feito no sentido de aperfeiçoar os recursos energéticos e hídricos, assim como melhorar a capacidade produtiva do homem sem prejudicar os recursos naturais. Neste cenário, projetos de reciclagem são essenciais para o reaproveitamento dos materiais utilizados e para o avanço da eficiência energética.

Diante deste contexto, o tema abordado neste estudo foi da logística reversa, sustentabilidade e a eficiência energética, pois se considera relevante as abordagens do tema com intuito de as organizações manterem-se competitivas e solidas dentro desse mercado global no qual estão inseridas e da preservação do meio ambiente.

\section{REVISÃO BIBLIOGRAFICA LOGÍSTICA}

O conceito de logística está associado às atividades de distribuição, armazenagem e transportes, onde visa disponibilizar bens e serviços gerados por uma empresa, atendendo ás necessidades do cliente a baixo custo.

Segundo Lambert (1998) definem:

O mundo já chamou a logística de diversas denominações: distribuição física, distribuição, engenharia de distribuição, logística empresarial, logística de marketing, logística de distribuição, administração de materiais, administração logística de materiais, administração de cadeia de abastecimento, dentre outras.

De acordo com LEITE (2009), "podemos identificar quatro aéreas da logística empresarial: a logística de suprimentos, que são ás ações necessárias para suprir as necessidades de insumos materiais da empresa; a logística de apoio á manufatura, responsável pelo planejamento, armazenamento e controle de fluxos internos; a logística de distribuição, responsável pela entrega dos pedidos recebidos e a logística reversa, que é mais nova área da logística, que tem como função o regresso dos produtos de pós-venda e pós-consumo e de seu endereçamento a diversos destinos".

\section{LOGÍSTICA REVERSA}

Existem vários estudos e pesquisas sobre logística reversa no mundo, seu conceito é bastante universal e significa em seu sentido mais compreensivo, todas as operações relacionadas com a reutilização de produtos e materiais, juntando-se todas as atividades logística de coletar, desmontar e processar produtos e/ou materiais e peças usadas a fim de garantir uma recuperação sustentável (LEITE, 2003).

A logística reversa tem como objetivo em minimizar a degradação do meio ambiente e reduzir as perdas de insumos, como a reutilização e reciclagem dos produtos. Exemplos: as indústrias, os supermercados, e as lojas, onde descartam volume significativo de material que podem ser reciclável como: papelão, papel, pallets de madeira, plástico, todos com grande potencial de reutilização ou de reciclagem, podemos definir também a logística reversa o retorno de produtos, redução na fonte, reciclagem, substituição de materiais, reuso de materiais, disposição de resíduos, reforma, reparação e remanufatura. (STOCK, 1998). 
Segundo Rogers e Tibben-Lembke (1998), o reaproveitamento de materiais e a economia com embalagens retornáveis têm trazido ganhos que estimulam cada vez mais iniciativas e energia para implantação da logística reversa, visando à eficiente recuperação de produtos. Podemos entender que o conceito da logística reversa é um processo complementar a logística tradicional, pois como a logística tradicional tem a função de levar produtos dos fornecedores até os seus clientes, a logística reversa deve completar o ciclo, trazendo de volta os produtos já utilizados dos diferentes pontos de consumo a sua origem (LACERDA, 2002).

\section{PROJETO CONTA CIDADÃ}

O projeto Conta Cidadã consiste na troca de lixo reciclável (denominados resíduos sólidos) por créditos financeiros na conta de energia elétrica dos consumidores, com destinação organizada do material coletado para uma indústria de reciclagem.

O programa conta cidadã tem como foco o incentivo à sociedade da troca de resíduos residências pela troca de bônus na conta de energia, a fim de aumentar a energia economizada e evitada nas fábricas, através da reciclagem dos materiais, tendo como foco o incentivo a coleta seletiva e conscientização da necessidade de preservação do meio ambiente.

Este projeto conta com 11 postos de coleta fixo, sendo (03 postos) na cidade de Presidente Prudente, (02 postos) em Assis, (02 postos) em Catanduva, (02 postos) em Bragança Paulista e (02 postos) em Guarapuava.

\section{BENEFÍCIOS}

\section{Para a Sociedade}

$>$ Desenvolvimento de uma metodologia de coleta Seletiva, com recompensa para adesão ao programa;

$>$ Diminuição da poluição e destinação correta de materiais recicláveis;

$>$ Diminuição de doenças e infecções transmitidas devido ao acúmulo de lixos;

$>$ Aumento do emprego e de oportunidade de desenvolvimento social dos integrantes da equipe do projeto seja de modo direto ou indireto;

$>$ Mudança cultural e conscientização do problema de reciclagem do lixo e dos benefícios do reprocessamento de materiais.

\section{Para Energisa}

> Incentivo às ligações elétricas legais e diminuição da clandestinidade;

$>$ Divulgação e melhoria da imagem da empresa;

$>$ Redução do nível de inadimplência;

$>$ Reforço e fortalecimento da marca, com expansão dos meios de divulgação (mídias, cartões, postos, etc..).

\section{Para a Comunidade Científica}

> As medições realizadas pelo projeto podem ser utilizadas em estudos relativos à eficiência energética e reciclagem de resíduos sólidos;

$>$ Os dados coletados e registrados dos consumidores cadastrados poderão ser utilizados em estudos relativos aos temas de reciclagem e coleta seletiva.

\section{METODOLOGIA}


A metodologia utilizada neste estudo foi de pesquisas bibliográficas constituída por livros, revistas científicas e artigos de congressos, também se utilizou métodos qualitativos e quantitativos.

O projeto conta cidadã será aplicado nas principais das concessionárias cooperadas da Energisa, abrangendo cinco cidades: Presidente Prudente, Assis, Catanduva, Bragança Paulista e Guarapuava, totalizando 11 postos de recolha. Os materiais reciclagem aderente ao programa são: Papel, Plástico, Metal e Caixinhas de leite Tetrapak. Serão analisado a quantidade de materiais reciclável recolhido verso quantidade de $\mathrm{MWh} / \mathrm{t}$ economizada pelo reaproveitamento dos materiais.

Os ganhos energéticos do programa serão baseados nos dados estudados pelo professor Doutor da USP Sabetai Calderoni, que determina a economia de energia por unidade de peso total do material coletado pela economia de energia no reprocessamento. Esses valores são demonstrados na tabela 1 abaixo;

Tabela 1 - Materiais a serem trabalhados e economia de energia elétrica

\begin{tabular}{|l|c|}
\hline \multicolumn{1}{|c|}{ Resíduo } & $\begin{array}{c}\text { Energia Elétrica Economizada } \\
\text { por tonelada } \\
\text { (MWh/t) }\end{array}$ \\
\hline Papel & 3,51 \\
\hline Plástico & 5,06 \\
\hline Metal & 5,30 \\
\hline Tetrapak & 3,95 \\
\hline
\end{tabular}

Fonte: Calderoni (2003)

A produção de produtos a partir de material reciclável é mais econômica que a partir de matérias-primas virgens, além de proporcionar economia de: energia, matérias-primas, água, controle ambiental, custo evitado de transporte e aterramento, também gera ganhos sociais, ambientais e de saúde publica.

\section{RESULTADOS}

O programa conta cidadã, "projeto troca de resíduos sólidos por bônus na conta de energia" teve seu inicio em outubro de 2015 e vai até Dezembro de 2017, onde obtivemos resultados bastante significativos dos materiais recicláveis recolhido, os consumidores das cinco cidades (Presidente Prudente, Assis, Catanduva, Bragança Paulista e Guarapuava) que aderiram ao programa, foram bastante participativos, pois até a presente data foram cadastradas 20.586 unidades consumidoras. Sendo coletado um total de 441.529 quilos de materiais recicláveis, conforme gráfico 1 abaixo;

Quantidade resíduos de materiais recolhido $(\mathrm{kg})$

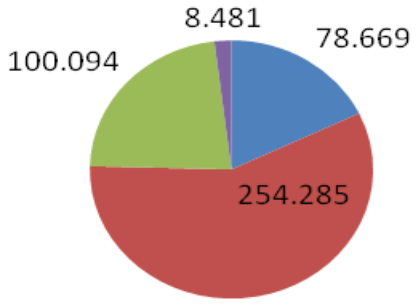

- Papel

- Plástico

- Metal

Tetrapak

Fonte: Autor 
Foram distribuídos créditos financeiros na conta de energia elétrica dos consumidores através do material coletado, chegando a um total $\mathrm{R} \$$ 108.000,00 (Cento e Oito Mil Reais) em bônus. Através desse programa todos consumidores cadastrados demonstraram uma mudança em seu comportamento, despertaram o interesse em ter uma atitude diferente em seu dia-a-dia em relação ao meio ambiente, ao invés de jogar resíduos de materiais no lixo, poluindo o planeta, preferem juntar esses resíduos e trocar por créditos na conta de energia, contribuindo desse modo na preservação do meio ambiente.

\section{CONSIDERAÇÕES FINAIS}

A logística reversa tem um papel fundamental para o meio ambiente, por se tratar de um tema novo dentro do cenário econômico, as empresas estão se adaptando ás novas exigências, inovando suas técnicas, investindo em tecnologias e em processos de aproveitamento de resíduos e reutilizá-los no ciclo de produção de produtos reciclável, contribuindo para a redução do uso de recursos naturais e dos demais impactos ambientais.

Os atuais cenários de mudanças profundas e complexas em todo o ambiente organizacional forçam as empresas a mudar suas políticas e metodologias de administração em relação ao meio ambiente, ou seja, para que as organizações possam permanecer solidas e competitivas, é preciso que as mesmas se preocupem com os impactos ambientais e sociais, respeitando todos os fatores econômico, tecnológico, ecológico, legal e social, contribuindo na manutenção e preservação do meio ambiente.

\section{REFERÊNCIAS BIBLIOGRÁFICAS}

CALDERONI, S. Os Bilhões perdido no lixo. 4. Ed. São Paulo: Editora Humanistas, 2003.

LACERDA, L. Logística reversa: uma visão sobre os conceitos básicos e as praticas. 2002.

LAMBERT, D.M.; Administração Estratégica da Logística. São Paulo: Vantine Consultoria, 1998.

LEITE, P.R. Logística reversa: meio ambiente e competitividade. 2.ed. São Paulo: Person, 2009.

LEITE, P.R. Logística reversa: meio ambiente e competitividade. São Paulo: Prentice Hall, 2003.

ROGERS, D. S.; TIBBEN-LEMBKE, R.S: Reverse Logistics Practice; IL: Reverse Logistics Exectuve Council, 1999.

STOCK, James R. Development and implementation of reverse logistics programs. Oak Brook, IL: Council of Logistics Management, 1998. 